\title{
Clinical spectrum of SCID: the key is in the thymus?
}

\author{
Mirjam van der Burg* and Menno C. van Zelm* \\ Department of Immunology, Erasmus MC, University Medical Center, Rotterdam, Netherlands \\ *Correspondence: m.vanderburg@erasmusmc.nl; m.vanzelm@erasmusmc.nl \\ Edited and reviewed by: \\ Luigi Daniele Notarangelo, Harvard Medical School, USA
}

Keywords: severe combined immunodeficiency, Omenn syndrome, thymic epithelial cells, hypomorphic mutation, T-cell, immune deregulation

\section{A commentary on}

Abnormalities of thymic stroma may contribute to immune dysregulation in murine models of leaky severe combined immunodeficiency

by Rucci F, Poliani PL, Caraffi S, Paganini T, Fontana E, Giliani S, Alt FW, Notarangelo LD. (2011) Front Immunol 2:15. doi:10. 3389/fimmu.2011.00015

Genetic defects in the recombination activating genes, RAG1 and RAG2 are known to impair $\mathrm{V}(\mathrm{D}) \mathrm{J}$ recombination in developing $\mathrm{B}$ and T-cells, thereby causing T-B-severe combined immunodeficiency (SCID) (1). Importantly, RAG defects with residual recombination activity (hypomorphic mutations) give rise to the Omenn syndrome, which is characterized by erythroderma, eosinophilia, hyper IgE, and the presence of oligoclonal autoreactive T-cells (2). In recent years, additional patients with RAG mutations were identified that presented with atypical clinical features, raising important questions regarding diagnosis, and treatment strategies (3). Furthermore, the underlying mechanism explaining how this clinical heterogeneity can be caused by mutations in these RAG genes remained unclear. Recently, Lee et al. determined the level of residual recombination activity of mutant RAG proteins and found that it correlated well with the clinical phenotype of the patients (4). However, this was only part of the story because IJspeert et al. showed that 22 patients with similar RAG mutations presented with different clinical presentations (5) Thus, the varying degrees of immune dysregulation in RAG-deficient patients cannot be predicted solely based on the RAG gene defect.

The study of Rucci et al. in Frontiers in Immunology provided new insight into the role of thymic stroma in immune regulation (6). Following earlier observations of abnormalities in thymic stroma and impaired expression of AIRE and tissue specific antigens (TSA) in thymus of Omenn syndrome patients $(7,8)$, the authors studied two murine models of leaky SCID: $\mathrm{rag}^{\mathrm{S} / S}$ mice with hypomorphic S723C substitutions in the rag1 gene and lig $4^{R / R}$ mice with $\mathrm{R} 278 \mathrm{H}$ mutations in the gene encoding DNA ligase IV. The rag1 ${ }^{S / S}$ mice display severe combined immunodeficiency with residual development of oligoclonal and functionally impaired T-cells, and some mice develop features consistent with Omenn syndrome (9). The $\operatorname{lig} 4^{R / R}$ mice have a leaky SCID phenotype without features of Omenn syndrome (10).

Both $\mathrm{rag} 1^{\mathrm{S} / S}$ and $\operatorname{lig} 4^{R / R}$ mice showed a significant reduction in thymus size and cellularity due to decreased absolute numbers of $\mathrm{CD}^{+}{ }^{+} \mathrm{CD} 8^{+}$double positive (DP) as well as of CD4 and CD8 single positive (SP) thymocytes. Thymic development was arrested incompletely at DN3 stage, consistent with a $\mathrm{V}(\mathrm{D}) \mathrm{J}$ recombination defect. Newly generated SP thymocytes in both models underwent maturation in the medulla, but this intra-thymic maturation was accelerated as evidenced by skewing toward a more mature phenotype, probably accompanied by homeostatic proliferation in a lymphopenic microenvironment (11). The rag1 $1^{S / S}$ and $\operatorname{lig} 4^{R / R}$ models differed in the diversity of the thymic TCR repertoire: this was polyclonal in thymocytes of $\operatorname{lig} 4^{R / R}$ mice, whereas $\mathrm{rag} 1^{\mathrm{S} / S}$ mice displayed a highly restricted TCR repertoire, similar to that of Omenn syndrome patients.

To study the nature of this difference, the authors subsequently focused on thymic epithelial cells (TEC). Cortical (c)TECs and medullary (m)TECs play a critical role in thymic selection and central tolerance (Figure 1A), and cross-talk with developing thymocytes is crucial for TEC maturation and for maintenance of thymic architecture (12). The thymic demarcation between the cortex and the medulla was preserved lig $4^{R / R}$ mice, whereas it was completely absent in $\mathrm{ragl}^{\mathrm{S} / S}$ mice. In $\mathrm{ragl}^{\mathrm{S} / S}$ mice, this disrupted architecture also resulted in the absence of AIRE-expressing mTECs. AIRE regulates the expression of genes encoding peripheral tissue-specific antigens (TSAs). Presentation of TSA peptides by mTECs or dendritic cells leads to tolerance via clonal deletion of self-reactive thymocytes or by facilitating differentiation into natural regulatory $\mathrm{T}$ (nTreg) cells. nTreg cells were severely reduced in number, but still displayed a regulatory function. This is in contrast to Omenn syndrome patients that show disturbed nTreg function.

In summary, the authors showed that the degree by which hypomorphic mutations impair T-cell development is associated with the defects in thymic stroma architecture and AIRE and TSA expression in mTECs. Especially, when the differentiation block only allows differentiation of a few thymocytes with a restricted TCR gene repertoire, the thymus defects lead to immune dysregulation. Both mouse models showed similar reduction in thymus size and cellularity. Still, $\operatorname{rag} 1^{\mathrm{s} / \mathrm{s}}$ mice showed a restriction in their TCR gene repertoire as compared with $\operatorname{lig} 4^{R / R}$. Thus, despite the differential impact of these mutations on $\mathrm{V}(\mathrm{D}) \mathrm{J}$ recombination, homeostatic processes in the thymus compensated the lower production in $\mathrm{rag}^{\mathrm{s} / \mathrm{s}}$ mice with additional proliferation. The association of immune dysregulation with TCR repertoire restriction has recently been confirmed through next generation sequencing of TCR $\beta$ gene rearrangements in patients with hypomorphic SCID and immune dysregulation (13). These patients had mutations in RAG1/2, the common $\gamma$ chain of the IL-2 receptor and $\zeta$-associated protein kinase 70 (ZAP70), which all affect 


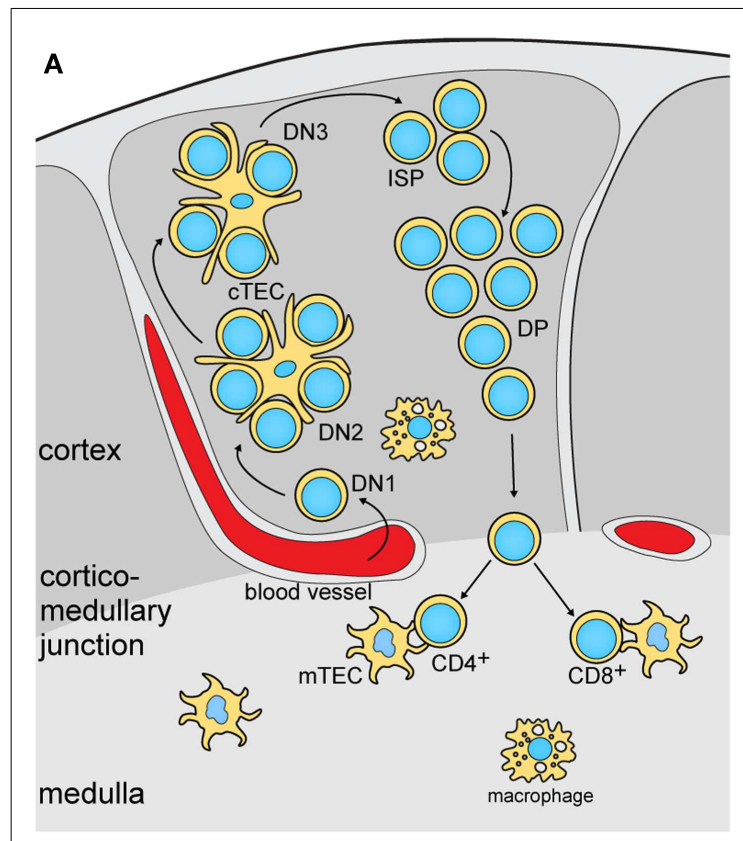

FIGURE 1 | Precursor T-cell differentiation in human thymus.

(A) Thymocyte differentiation and their migration through the anatomic niches. The earliest double negative (DN) thymocytes enter the thymus at the cortico-medullary junction and migrate to the sub-capsular zone. In humans, 3 DN subsets can be identified: DN1, CD34+CD38- CD1 ${ }^{-}$ DN2, CD34 ${ }^{+} \mathrm{CD} 38^{+}{ }^{C} D 1 a^{-} ; \mathrm{DN} 3, \mathrm{CD} 34^{+} \mathrm{CD} 38^{+} \mathrm{CD} 1 \mathrm{a}^{+}(14)$.

Subsequently, these upregulate CD4 and become immature single
B

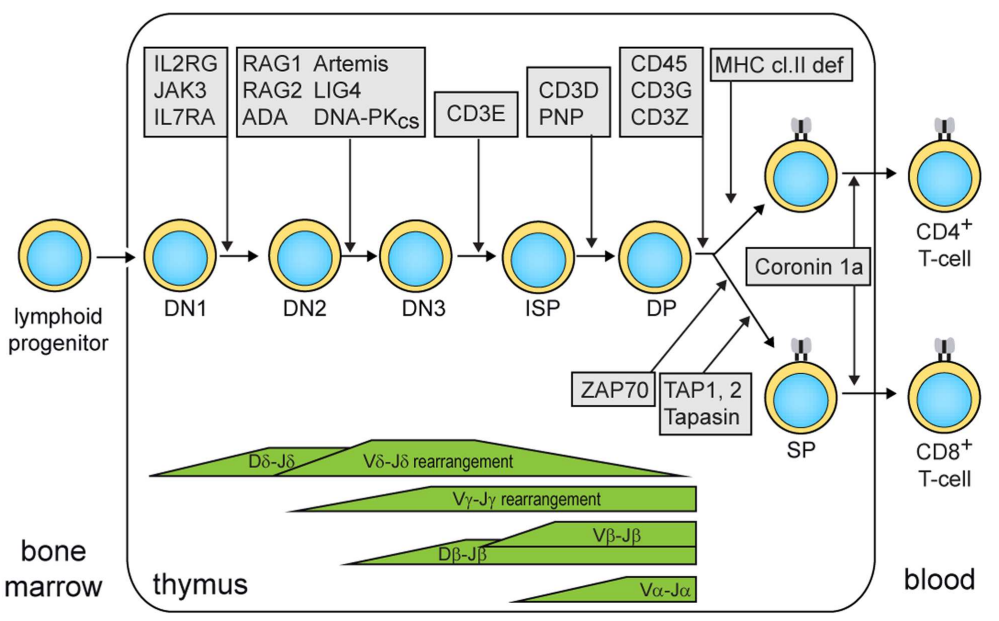

positive (ISP), followed by $\mathrm{CD}^{+}{ }^{+} \mathrm{CD} 4^{+} \mathrm{CD} 8^{+}$double positive (DP) and finally into $\mathrm{CD}^{+}{ }^{+} \mathrm{CD} 4^{+}$or $\mathrm{CD}^{+}{ }^{+} \mathrm{CD} 8^{+}$single positive (SP) cells while passing through the cortex and the medulla. (B) Human T-cell differentiation stages including $V(D) J$ recombination bars (14) and genetic defects underlying PID that result in impaired precursor differentiation. The indicated developmental blocks largely rely on data from targeted mutation studies in the mouse.
T-cell differentiation prior to the SP stage (Figure 1B).

Thus, the article by Rucci et al. has begun to provide a rationale for the various degrees of immune dysregulation in patients with Omenn syndrome or atypical SCID. Central tolerance in the thymus appears to play a key role and seems to be influenced by the combination of the generated TCR repertoire and the "TSA repertoire" as expressed by mTECs and DC. The clinical phenotype of hypomorphic mutations will depend on the level of residual activity of the affected protein, the number, the immunophenotype, and clonality of the generated thymocytes, and via these on the thymic architecture and the number and "diversity" of mTECs. The prospects of high-throughput sequencing of TCR gene rearrangements will likely provide further insights into the diversity in immune dysregulation in SCID.

\section{ACKNOWLEDGMENTS}

The authors thank Mrs. S. de BruinVersteeg for assistance with preparing the
Figure. Mirjam van der Burg is supported by Vidi grant 91712323 from ZonMW/NWO, and Menno C. van Zelm by an Erasmus MC Fellowship.

\section{REFERENCES}

1. Schwarz K, Gauss GH, Ludwig L, Pannicke U, Li $\mathrm{Z}$, Lindner $\mathrm{D}$, et al. RAG mutations in human B cell-negative SCID. Science (1996) 274:97-9. doi:10.1126/science.274.5284.97

2. Villa A, Santagata S, Bozzi F, Giliani S, Frattini A, Imberti L, et al. Partial V(D)J recombination activity leads to Omenn syndrome. Cell (1998) 93:885-96. doi:10.1016/S0092-8674(00)81448-8

3. Niehues T, Perez-Becker R, Schuetz C. More than just SCID - the phenotypic range of combined immunodeficiencies associated with mutations in the recombinase activating genes (RAG) 1 and 2 . Clin Immunol (2010) 135:183-92. doi:10.1016/j. clim.2010.01.013

4. Lee YN, Frugoni F, Dobbs K, Walter JE, Giliani S, Gennery AR, et al. A systematic analysis of recombination activity and genotype-phenotype correlation in human recombination-activating gene 1 deficiency. J Allergy Clin Immunol (2013). doi:10. 1016/j.jaci.2013.10.007

5. IJspeert H, Driessen GJ, Moorhouse MJ, Hartwig NG, Wolska-Kusnierz B, Kalwak K, et al. Similar recombination-activating gene (RAG) mutations result in similar immunobiological effects but in different clinical phenotypes. J Allergy Clin Immunol (2014). doi:10.1016/j.jaci.2013.11.028

6. Rucci F, Poliani PL, Caraffi S, Paganini T, Fontana E, Giliani S, et al. Abnormalities of thymic stroma may contribute to immune dysregulation in murine models of leaky severe combined immunodeficiency. Front Immunol (2011) 2:15. doi:10. 3389/fimmu.2011.00015

7. Cavadini P, Vermi W, Facchetti F, Fontana S, Nagafuchi S, Mazzolari E, et al. AIRE deficiency in thymus of 2 patients with Omenn syndrome. J Clin Invest (2005) 115:728-32. doi:10.1172/ JCI23087

8. Poliani PL, Facchetti F, Ravanini M, Gennery AR, Villa A, Roifman CM, et al. Early defects in human T-cell development severely affect distribution and maturation of thymic stromal cells: possible implications for the pathophysiology of Omenn syndrome. Blood (2009) 114:105-8. doi: 10.1182/blood-2009-03-211029

9. Walter JE, Rucci F, Patrizi L, Recher M, Regenass S, Paganini T, et al. Expansion of immunoglobulinsecreting cells and defects in B cell tolerance in Rag-dependent immunodeficiency. J Exp Med (2010) 207:1541-54. doi:10.1084/jem. 20091927

10. Rucci F, Notarangelo LD, Fazeli A, Patrizi L, Hickernell T, Paganini T, et al. Homozygous DNA ligase IV R278H mutation in mice leads to leaky SCID and represents a model for human LIG4 syndrome. Proc Natl Acad Sci U S A (2010) 107:3024-9. doi:10.1073/pnas.0914865107 
11. Datta S, Sarvetnick N. Lymphocyte proliferation in immune-mediated diseases. Trends Immunol (2009) 30:430-8. doi:10.1016/j.it.2009. 06.002

12. Shores EW, Van Ewijk W, Singer A. Disorganization and restoration of thymic medullary epithelial cells in T cell receptor-negative scid mice: evidence that receptor-bearing lymphocytes influence maturation of the thymic microenvironment. Eur J Immunol (1991) 21:1657-61. doi:10.1002/eji. 1830210711

13. Yu X, Almeida J, Darko S, van der Burg M, Deravin SS, Malech H, et al. Human syndromes of immunodeficiency and dysregulation are characterized by distinct defects in T-cell receptor repertoire development. J Allergy Clin Immunol (2014). doi:10. 1016/j.jaci.2013.11.018

14. Dik WA, Pike-Overzet K, Weerkamp F, de Ridder D, de Haas EF, Baert MR, et al. New insights on human $\mathrm{T}$ cell development by quantitative $\mathrm{T}$ cell receptor gene rearrangement studies and gene expression profiling. J Exp Med (2005) 201:1715-23. doi:10.1084/jem.20042524

Received: 13 February 2014; paper pending published: 23 February 2014; accepted: 04 March 2014; published online: 19 March 2014.
Citation: van der Burg Mand van Zelm MC (2014) Clinical spectrum of SCID: the key is in the thymus? Front. Immunol. 5:111. doi: 10.3389/fimmu.2014.00111

This article was submitted to Primary Immunodeficiencies, a section of the journal Frontiers in Immunology. Copyright (C) 2014 van der Burg and van Zelm. This is an open-access article distributed under the terms of the Creative Commons Attribution License (CC BY). The use, distribution or reproduction in other forums is permitted, provided the original author(s) or licensor are credited and that the original publication in this journal is cited, in accordance with accepted academic practice. No use, distribution or reproduction is permitted which does not comply with these terms. 